\title{
UREA METABOLISM IN MAN*
}

\author{
By MACKENZIE WALSER † AND LEONARD J. BODENLOS \\ (From the Naval Medical Research Institute, National Naval Medical Center, Bethesda, Md. and the \\ Laboratory of Kidney and Electrolyte Metabolism, National Heart Institute, \\ National Institutes of Health, Bethesda, Md.)
}

(Submitted for publication March 26, 1959; accepted May 14, 1959)

Urea has long been considered to be metabolically inert. However, recent studies with isotopic urea in several species of animals have revealed that urea is hydrolyzed in the alimentary tract even when administered parenterally (1-5). This breakdown is presumably due to the action of bacterial urease, since urea metabolism can be eliminated or reduced to negligible proportions by the administration of antibiotics.

In the studies reported herein, labeled urea was administered intravenously to normal subjects and the rate of extrarenal disposal was determined. Both $\mathrm{N}^{15}$ - and $\mathrm{C}^{14}$-labeled materials were employed in order to minimize the problem of reincorporation of tracer atoms into urea. In the case of $\mathrm{N}^{15}$, enriched ammonia produced by urea hydrolysis in the gut becomes reincorporated into newly formed urea. In the case of $\mathrm{C}^{14}$, recent evidence (6) suggests that reincorporation into urea of labeled $\mathrm{CO}_{2}$, formed by bacterial ureolysis in the gut, may also occur; a conclusion supported by the present experiments.

Despite these limitations, the results indicate that 15 to 30 per cent of the urea being synthesized in normal subjects is continually being destroyed. This breakdown can be eliminated by oral administration of neomycin.

\section{METHODS}

Urea containing 60.9 atoms per cent $\mathrm{N}^{15}$ was synthesized by the ammonolysis of diphenyl carbonate (7) and purified by recrystallization. ${ }^{1}$ The resulting product had a melting point of $130^{\circ} \mathrm{C}$. (uncorrected). The nitrogen content was 46.7 per cent (calculated 46.7 per cent).

* An abstract of this work has been published (Urea breakdown in normal man. J. clin. Invest. 1957, 36, 933). The opinions presented herein are those of the authors and do not necessarily reflect the views of the United States Navy.

† Formerly Lieutenant, Medical Corps, USNR. Present address: Johns Hopkins School of Medicine, Baltimore, Md.

$\ddagger$ Lieutenant Commander, Medical Service Corps, USN.

${ }^{1}$ Dr. W. J. McCarville kindly carried out this synthesis.
$\mathrm{C}^{14}$-labeled urea containing $1 \mathrm{mc}$. of $\mathrm{C}^{14}$ per mMole was obtained from Volk Laboratories under authorization by the Atomic Energy Commission. Both preparations were prepared for use by dissolving in sterile saline solution. Tests for pyrogenicity and bacterial contamination were negative.

The subjects were normal healthy volunteers who continued their usual meals and activities during the studies. One glass of water per hour was ingested for four to eight hours following administration of labeled urea. Urinary catheters were not employed.

Measured portions of labeled urea (25 to $100 \mathrm{mg}$. of $\mathrm{N}^{16}$-urea or $2.5 \mu \mathrm{c}$. of $\mathrm{C}^{14}$-urea) were injected intravenously. At intervals, venous blood samples were obtained, and immediately thereafter, the subjects voided. In the $\mathrm{N}^{16}$ experiments, the urine samples were acidified immediately to prevent loss of ammonia.

The nitrogen content and atoms per cent excess $\mathrm{N}^{15}$ were determined in urinary ammonia, urea and total nitrogen and in serum urea. Urine ammonia was isolated on permutit which was then washed five times with distilled water. Ammonia-free urine and a tungstic acid filtrate of serum were treated with urease according to the method of Van Slyke and Cullen (8). A sample of urine was also subjected to Kjeldahl digestion overnight. After the addition of alkali, ammonia from these various fractions was steam distilled into boric acid solution and titrated with $0.1 \mathrm{~N} \mathrm{HCl}$. The recovery of urea was determined simultaneously in each experiment and averaged 98 per cent. The solutions remaining after titration were evaporated to a small volume and allowed to react with sodium hypobromite in Rittenberg tubes. The atoms per cent $\mathrm{N}^{16}$ in the evolved nitrogen gas was determined in the mass spectrometer (Consolidated model 21-201). Atoms per cent excess $\mathrm{N}^{15}$ was determined by subtracting values for atoms per cent $\mathrm{N}^{16}$ in control samples of blood and urine. Compared to an ammonium chloride standard, the control samples contained a biological excess of $\mathrm{N}^{15}$ of less than 0.004 atoms per cent. The maximum error of the $\mathrm{N}^{16}$ analyses was \pm 0.002 atoms per cent.

In the $\mathrm{C}^{14}$ experiments, total urea was determined by the method of Conway (9). . $\mathrm{C}^{14}$-urea was determined as follows : aliquots of blood or urine were acidified with $\mathrm{HCl}$ and shaken with a few drops of caprylic alcohol in order to remove all bicarbonate. Sufficient alkali was added to restore the $\mathrm{pH}$ to approximately 7 , and aliquots were placed in $50 \mathrm{ml}$. flasks containing a center well. One $\mathrm{ml}$. of 3 per cent urease solution (Sigma Chemical Co.) and $1 \mathrm{ml}$. of phosphate buffer, $\mathrm{pH}$ 7.2, were added and the flasks were stoppered. After 20 minutes shaking at $37^{\circ} \mathrm{C}$., dilute $\mathrm{H}_{2} \mathrm{SO}_{4}$ was injected through the stopper. Shaking was 
continued for another hour. In the earlier experiments, the center well contained 25 per cent $\mathrm{NaOH}, \mathrm{CO}_{2}$-free, which was transferred to centrifuge tubes, mixed with 10 ml. 1 per cent $\mathrm{BaCl}_{2}$ in $\mathrm{CO}_{2}$-free water, and centrifuged. The precipitated barium carbonate was washed with $\mathrm{CO}_{2}$ free 50 per cent ethanol, suspended in 95 per cent ethanol and transferred to weighed planchets. The planchets were dried, reweighed and counted in a flow counter for a total of 10,000 counts. After correction for background and self-absorption, the results were expressed in terms of an aliquot of the injected solution analyzed simultaneously.

In the later experiments, the center well contained 0.2 $\mathrm{ml}$. of Hyamine ${ }^{\circledR}, 0.5 \mathrm{~N}$. This was transferred with the aid of $1.5 \mathrm{ml}$. toluene to specimen vials, mixed with $15 \mathrm{ml}$. toluene containing diphenyl oxazole, $1 \mathrm{~N}$, capped, cooled and counted in a Tri-Carb liquid scintillation counter for a total of 5,000 counts. The results were expressed in terms of an aliquot of the injected solution analyzed simultaneously.

\section{CALCULATIONS}

When a trace quantity, $M$, of a substance normally present in the blood is injected intravenously, the tracer molecules become mixed with the native molecules present in the blood and in the interstitial fluid. Under certain conditions the tracer molecules eventually become evenly mixed with all of the native substance present in the body in an exchangeable form. Although this completely uniform ratio of tracer to native molecules is theoretically unobtainable except in a closed system, for practical purposes an equilibrium distribution may be obtained because the rates of excretion and/or metabolic destruction are slow relative to the rate of equilibration.

If the rates of formation, $A$, excretion, $U$, and metabolic destruction, $F$, of the native substance remain constant during the period of observation, and if

$$
\mathrm{A}=\mathrm{U}+\mathrm{F},
$$

then the plasma concentration, $\mathrm{P}$, of native substance will remain constant, as will VP, the total amount in the body, where $\mathrm{V}$ is its apparent volume of distribution (assuming that $\mathrm{V}$ does not change).

Following equilibration of injected tracer, the amount, $M_{t}$, of tracer remaining at any given time, $t$, will decline at a rate given by the turnover rate of native substance, A/VP. It is assumed here that no tracer returns to the pool once metabolized:

Integrating

$$
-\mathrm{dM}_{\mathrm{t}} / \mathrm{dt}=\frac{\mathrm{A}}{\mathrm{VP}} \mathrm{M}_{\mathrm{t}}
$$

$$
\ln \mathrm{M}_{\mathrm{t}}=-\frac{\mathrm{A}}{\mathrm{VP}} \mathrm{t}+\mathrm{C},
$$

where $\mathrm{C}$ is the constant of integration. When $\mathrm{t}=0$, $M_{t}=M$. However, the extrapolated value $($ at $t=0)$ of $\mathbf{M}_{t}, \mathbf{M}_{\mathrm{o}}$, is likely to be less than the injected dose, $M$, by a variable amount; this is due to the fact that the average plasma concentration of tracer during the period of equilibration (and therefore the amount excreted) is greater than if equilibration had occurred instantaneously. Let $x$ designate the difference between the extrapolated intercept value, $\mathbf{M}_{0}$, and the amount injected, $M$ (which is the intercept value which would have obtained if equilibration had occurred instantaneously):

$$
\mathbf{M}_{\mathrm{o}}=\mathbf{M}-\mathbf{x} .
$$

Substituting in Equation 3, we have, for any time greater than the equilibration period:

$$
M_{t}=(M-x) e^{-(A / V P) t} .
$$

The apparent volume of distribution, $\mathrm{V}$, is given by:

$$
\mathrm{V}=\frac{\mathrm{M}_{\mathrm{o}}}{\mathrm{p}_{\mathrm{o}}}=\frac{\mathrm{M}-\mathrm{x}}{\mathrm{p}_{\mathrm{o}}},
$$

where $p_{o}$ is the intercept value of the plasma concentration of tracer. The plasma concentration of tracer at time $t$, $p_{t}$ (where $t$ is greater than the equilibration period), is

$$
\mathrm{p}_{\mathrm{t}}=\mathrm{p}_{\mathrm{o}} \mathrm{e}^{-(\mathbf{A} / \mathbf{V P}) \mathrm{t}} \text {. }
$$

Therefore, $p_{o}$ and A/VP may be derived from observations of $p_{t}$. In order to calculate $V$ it is necessary to have an estimate of $\mathrm{x}$, as Equation 6 shows.

If the rate of excretion of native substance, $U$, is large with respect to the rate of metabolism, F, then a good estimate of $\mathrm{x}$ can be obtained by observing the excretion of tracer, as shown in the following derivation.

The rate of renal (or renal plus extrarenal) excretion of tracer, $u_{t}$, is determined by the fact that the specific activities (or, in the case of stable isotopes, the atoms per cent excess) in blood and urine are equal with the qualifications noted below:

$$
\frac{\mathrm{u}_{\mathrm{t}}}{\mathrm{U}}=\frac{\mathrm{p}_{\mathrm{t}}}{\mathrm{P}}
$$

Substituting for $\mathrm{p}_{\mathrm{t}}$ from Equation 7,

$$
\mathrm{u}_{\mathrm{t}}=\frac{\mathrm{U}}{\mathrm{P}} \mathrm{p}_{\mathrm{o}} \mathrm{e}^{-(\mathrm{A} / \mathrm{VP}) \mathrm{t}}
$$

The total amount of tracer, $S$, excreted up to time $t$ (provided that $t$ is greater than the equilibration period) is therefore:

$$
\mathrm{S}=\mathrm{x}+\int_{\mathrm{o}}^{\mathrm{t}} \mathrm{u}_{\mathrm{t}}=\mathrm{x}+\frac{\mathrm{UV \textrm {p } _ { \mathrm { o } }}}{\mathrm{A}}\left[1-\mathrm{e}^{-(\mathrm{A} / \mathrm{VP}) \mathrm{t}}\right]
$$

Dividing by $M$, the amount of tracer injected, we have

$$
\frac{\mathrm{S}}{\mathrm{M}}=\frac{\mathrm{x}}{\mathrm{M}}+\frac{\mathrm{UVp_{ \textrm {o } }}}{\mathrm{AM}}\left[1-\mathrm{e}^{-(\mathrm{A} / \mathrm{VP}) \mathrm{t}}\right] \text {. }
$$

This equation can be treated as a straight line function of $t_{\text {wo variables, viz., } S / M}$ and $\left[1-\mathrm{e}^{-(\mathrm{A} / \mathrm{VP}) t}\right]$, following the suggestion of Berkson, Keating, Power and McConahey (10). The intercept is $\mathrm{x} / \mathrm{M}$. Knowing the ratio A/VP and the fraction S/M excreted at each time interval, it is therefore possible to plot these fractions against values of $\left[1-\mathrm{e}^{-(\mathbf{A} / \mathrm{VP}) t}\right]$ and obtain $\mathrm{x} / \mathrm{M}$ as the intercept.

A further complication is introduced by the fact that tracer removed from the blood by the kidneys requires an appreciable time, $d$, to reach the bladder. The specific activity of urine collected at time, $t$, therefore reflects the specific activity of plasma at an earlier time, $t-d$.

$$
\frac{u_{t} / U}{p_{t} / P}=\frac{p_{(t-d)} / P}{p_{t} / P}=\frac{p_{o} e^{-(A / V P)(t-d)}}{p_{o} e^{-(A / V P) t}}=e^{(A / V P) d},
$$


where $u_{t}$ represents the observed rate of excretion of tracer at time, $t$, as distinguished from the true rate. The "mean urinary delay time," $d$, can thus be estimated by comparing simultaneous specific activity of blood and urine. Solving Equation 12 for d,

$$
\mathrm{d}=\frac{\mathrm{VP}}{\mathrm{A}} \ln \frac{\mathrm{u}_{\mathrm{t}} / \mathrm{U}}{\mathrm{p}_{\mathrm{t}} / \mathrm{P}} .
$$

The fraction of the injected tracer collected up to time, $t$, designated as $\mathrm{S}^{\prime} / \mathrm{M}$, is :

$$
\frac{S^{\prime}}{M}=\frac{x}{M}+\frac{U V p_{o}}{A M}\left[1-e^{-(A / V P)(t-d)}\right],
$$

where $t$ is greater than the sum of the time for equilibration and the urinary delay time. After this interval, the quantity, $x$, will have been excreted and further excretion will follow Equation 9.

Thus, the steps in calculating $\mathrm{V}$ and $\mathrm{F}$ from the plasma and urinary curves of tracer are as follows:

1) The turnover rate $A / V P$ is obtained as the slope of the line relating log plasma concentration to time using values obtained after equilibration.

2) The "delay time," $d$, is obtained from Equation 13 and averaged for each experiment.

3) Values of $\left[1-\mathrm{e}^{-(\mathrm{A} / \mathrm{VP})(\mathrm{t}-\mathrm{d})}\right]$ are plotted against $\mathrm{S}^{\prime} / \mathrm{M}$, and the intercept $\mathrm{x} / \mathrm{M}$ is found.

4) $\mathrm{V}$ is calculated from Equation 6.

5) The production rate, $A$, is obtained as the product of the slope, A/VP, by the pool size, VP.

6) The rate of metabolism, $F$, is calculated by subtracting the rate of urinary excretion, $U$, from A (Equation 1). ${ }^{2}$

The assumptions made in this treatment are: 1) The amount of injected material is negligible in relation to the amount present in the body. 2) The tracer molecules are handled in a manner identical to the native molecules. 3) The volume of distribution remains constant during the period of sampling. 4) The rates of formation, excretion and destruction of native substance remain constant. 5) The rate of excretion is large in relation to the rate of metabolic destruction. 6) Metabolized tracer does not return to the pool.

Under the conditions of our experiments, $\mathrm{N}^{15}$-labeled urea and $\mathrm{C}^{14}$-labeled urea both appear to fulfill all of these assumptions except the last: 1) The dose of $\mathrm{N}^{15}$-urea injected was about 1.5 per cent of the pool size in one experiment and less than 0.4 per cent in the other four. The dose of $\mathrm{C}^{14}$-labeled urea injected was negligible in relation to the urea pool. 2) Isotope effects with these labeled forms of urea can be predicted to be small (11) although no definitive data are available. 3) Urea diffuses very rapidly and attains a constant volume of distribution (12). 4) Since the plasma concentration of ordinary urea

${ }^{2} \mathrm{U} / \mathrm{A}$ may also be obtained from the slopes of the lines obtained in Step 3. This method (10) gives greater weight to the urinary data than the method outlined above. Since the collection and timing of samples is considerably more reliable for plasma than for urine, we have employed the urinary data only to obtain an estimate of the quantity, $x$. remained nearly constant in these experiments, and the rate of urea excretion showed only minor fluctuations (the maximum deviation from the mean for each experiment in any single period was 9 per cent and the average deviation was 4 per cent for all periods), the steady state conditions were apparently fulfilled. 5) The rate of excretion of urea is considerably greater than the rate of metabolism. 6) Although tracer atoms evidently returned to the urea pool in both the $\mathrm{N}^{15}$ and $\mathrm{C}^{14}$ experiments, the effect on the calculated rate of metabolism is to make it appear smaller than the true rate (see Discussion).

\section{RESULTS}

The experiments were of two types: 1) those in which plasma and urine samples were obtained at intervals of one to three hours, from which the production rate of urea can be calculated; and 2) those in which urine was collected for several days in order to determine the recovery of labeled material in the urine. One experiment with $\mathrm{N}^{15}$ combined the features of both types of study. The results of this experiment are shown in Table I. Following the injection of $\mathrm{N}^{15}$-urea, labeled nitrogen atoms appeared in urinary ammonia and urinary undetermined nitrogen. The atoms per cent excess $\mathrm{N}^{15}$ in these fractions remained less than that in urinary urea. The fraction of the dose excreted as urea was 79.5 per cent, as ammonia, 0.4 per cent and as total nitrogen, 89.6 per cent.

More detailed analysis of these data as well as the other experiments follow.

\section{Curve of plasma disappearance}

Figure 1 represents the atoms per cent excess $\mathrm{N}^{15}$ or specific activity of $\mathrm{C}^{14}$ in blood urea for all of the experiments of the first type plotted on a semilogarithmic scale. The first samples were obtained at least 90 minutes after injection, as suggested by earlier studies $(12,13)$. In all but one experiment, the decline in " $p$ " with time is linear on this logarithmic scale. These slopes were calculated by the method of least squares. However, in one individual given $\mathrm{C}^{14}$, Subject $\mathrm{E}$, the decline is not a simple exponential function but involves another slower component or components. This change in slope is probably due to the reincorporation of labeled atoms into newly formed urea. No attempt was made to calculate production rate in this experiment. Of the nine experiments illustrated in Figure 1, only 
TABLE I

Labeled nitrogen in plasma and urine following intravenous injection of $N^{15}-u r e{ }^{*} \dagger$

\begin{tabular}{|c|c|c|c|c|c|c|c|c|c|c|c|c|c|c|c|}
\hline \multirow[b]{2}{*}{ Time } & \multicolumn{2}{|c|}{ Serum urea $\mathrm{N}$} & \multirow[b]{2}{*}{$\begin{array}{c}\text { Urine } \\
\text { vol. }\end{array}$} & \multicolumn{4}{|c|}{ Urine urea $\mathrm{N}$} & \multicolumn{4}{|c|}{ Urine ammonia $\mathrm{N}$} & \multicolumn{4}{|c|}{ Urine total $\mathrm{N}$} \\
\hline & Conc. & $N^{15}$ & & Conc. & $N^{15}$ & $N^{15}$ & $\begin{array}{l}\text { Cum. } \\
\text { dose }\end{array}$ & Conc. & $\mathrm{N}^{15}$ & $\mathrm{~N}^{15}$ & $\begin{array}{l}\text { Cum. } \\
\text { dose }\end{array}$ & Conc. & $\mathrm{N}^{15}$ & $N^{15}$ & $\begin{array}{l}\text { Cum. } \\
\text { dose }\end{array}$ \\
\hline \multirow{2}{*}{$\begin{array}{c}\text { hrs. } \\
\mathbf{0}\end{array}$} & mg. \% & $a \%$ & $m l$. & $m g . \%$ & $a \%$ & $m g$. & $\%$ & $m g . \%$ & $a \%$ & $m g$. & $\%$ & $m g . \%$ & $a \%$ & $m g$. & $\%$ \\
\hline & 152 & 0270 & 1,080 & 131 & 0.415 & 5.86 & 19.7 & 4.2 & 0.086 & 0.04 & 0.1 & 165 & 0.373 & 6.64 & 22.5 \\
\hline 2.0 & 148 & 0.217 & 355 & 342 & 0.287 & 3.49 & 31.4 & 18.8 & 0.029 & 0.02 & 0.2 & 435 & 0.252 & 3.89 & 35.4 \\
\hline 4.1 & 152 & 0.202 & 290 & 446 & 0.227 & 2.94 & 41.3 & 25.7 & 0.010 & 0.01 & 0.2 & 566 & 0.197 & 3.22 & 46.2 \\
\hline 6.1 & 152 & 0143 & 315 & 357 & 0.177 & 1.98 & 48.0 & 18.6 & 0.013 & 0.01 & 0.2 & 446 & 0.156 & 2.19 & 53.6 \\
\hline 8 & 173 & 0.022 & 1,600 & 662 & 0.070 & 7.46 & 73.0 & 26.2 & 0.003 & 0.01 & 0.3 & 845 & 0.061 & 8.25 & 81.3 \\
\hline 32 & 17.5 & 0.004 & 1,290 & 853 & 0.011 & 1.21 & 77.1 & 41.9 & 0.002 & 0.01 & 0.3 & 1,088 & 0.010 & 1.36 & 85.9 \\
\hline 56 & 14.1 & 0.000 & 2,220 & 561 & 0.004 & 0.44 & 78.6 & 24.0 & 0.002 & 0.01 & 0.4 & 723 & 0.003 & 0.51 & 87.7 \\
\hline 79 & & & 2,080 & 405 & 0.001 & 0.09 & 78.9 & 22.6 & 0.001 & 0.00 & 0.4 & 529 & 0.001 & 0.15 & 88.2 \\
\hline \multirow{2}{*}{130} & 174 & 0.000 & 2,335 & 744 & 0.001 & 0.19 & 79.5 & 30.7 & 0.001 & 0.01 & 0.4 & 936 & 0.001 & 0.31 & 89.2 \\
\hline & & & 1,510 & 605 & 0.000 & 0.00 & 79.5 & 29.3 & 0.001 & 0.01 & 0.4 & 758 & 0.001 & 0.15 & 89.6 \\
\hline
\end{tabular}

* Experiment A1: $100 \mathrm{mg}$. urea containing 60.9 atoms per cent $\mathrm{N}^{15}$ injected at time zero (normal male, $74.1 \mathrm{Kg}$.). $\dagger \mathrm{N}^{15}$ expressed as excess above control samples. Blood and urine samples were obtained simultaneously.

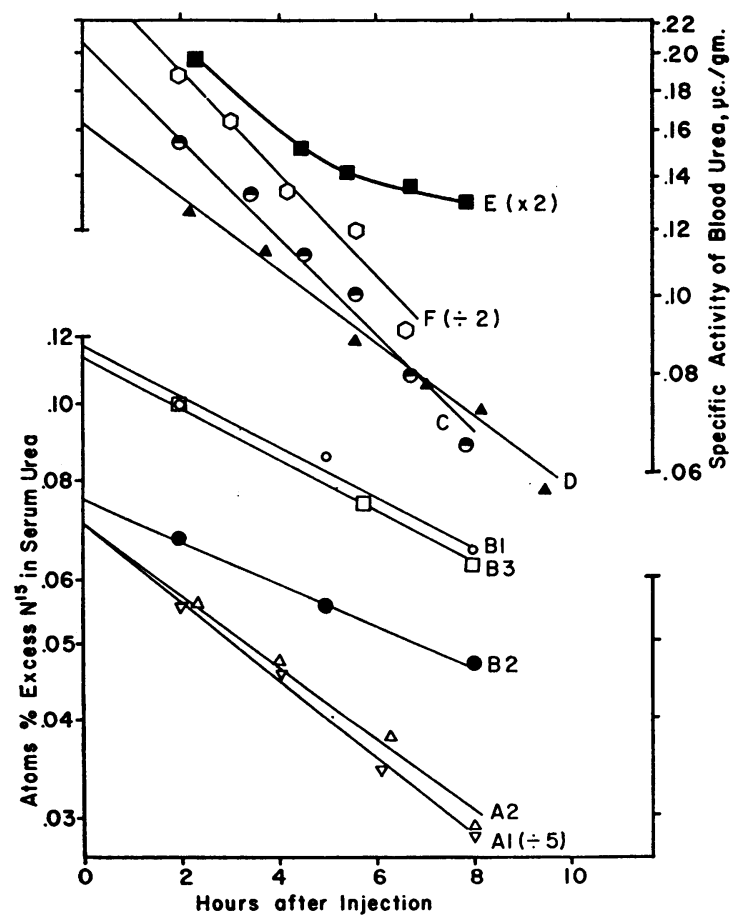

Fig. 1. The Ratio of Labeled to Unlabeled Urea Molecules in Blood at Intervals Following Intravenous InJection of Either $\mathrm{C}^{14}$-UREa (ABOve) OR $\mathrm{N}^{15}$ UREA (BELOW)

In Subjects $E$ and $F$ and in the first experiment in Subject $A$ the results have been multiplied by constant factors in order to include them all in the same figure. six were considered to fulfill the requirements for calculation of the rate of urea metabolism. In $\mathrm{F}$, the urine samples were lost. In $\mathrm{D}$, the plasma concentration of unlabeled urea exhibited a progressive decline during the experiment; consequently the steady state conditions were not fulfilled.

\section{2. "Urinary delay time"}

Inspection of the data in Table I reveals that the degree of enrichment of urinary urea nitrogen is greater than the average enrichment of plasma urea nitrogen during the same interval. The average plasma value, $\overline{\mathrm{p}} / \mathrm{P}$, may be calculated as follows:

$$
\overline{\mathrm{p}} / \mathrm{P}=\frac{\mathrm{p}_{1} / \mathrm{P}_{1}-\mathrm{p}_{2} / \mathrm{P}_{2}}{\ln \left(\mathrm{p}_{1} / \mathrm{P}_{1}\right) /\left(\mathrm{p}_{2} / \mathrm{P}_{2}\right)}
$$

The ratio of urinary urea enrichment (or specific activity) to plasma urea enrichment (or specific activity) has been calculated for the six technically satisfactory experiments. The results are shown in Table II. The proportion of labeled to unlabeled molecules is slightly greater in the urine than in the blood in all but one of the 19 periods. Using the measured slope of plasma disappearance (Figure 1), a "urinary delay time" may be calculated using Equation 13. The aver- 
TABLE II

Apparent urinary delay time for urea

\begin{tabular}{|c|c|c|c|c|}
\hline Expt. & Time & $\begin{array}{c}\text { Ratio } \\
(\mathrm{u} / \mathrm{U}) /(\mathrm{p} / \mathrm{P})\end{array}$ & Delay & $\begin{array}{l}\text { Urine } \\
\text { flow }\end{array}$ \\
\hline A1 & $\begin{array}{c}\text { hrs. } \\
2.0-4.1 \\
4.1-6.1 \\
6.1-8.0 \\
8-32 \\
32-56\end{array}$ & $\begin{array}{l}1.12 \\
1.13 \\
1.12 \\
1.09 \\
1.09\end{array}$ & $\begin{array}{l}\text { hrs. } \\
1.0 \\
1.1 \\
1.0 \\
1.2 \\
1.2\end{array}$ & $\begin{array}{c}m l . / m i n \\
2.9 \\
2.4 \\
2.8 \\
1.1 \\
0.9\end{array}$ \\
\hline A2 & $\begin{array}{l}2.2-4.0 \\
4.0-6.3 \\
6.3-8.0\end{array}$ & $\begin{array}{l}1.07 \\
1.11 \\
1.14\end{array}$ & $\begin{array}{l}0.6 \\
1.0 \\
1.2\end{array}$ & $\begin{array}{l}5.0 \\
5.5 \\
3.3\end{array}$ \\
\hline B1 & $\begin{array}{l}2.0-5.0 \\
5.0-8.0\end{array}$ & $\begin{array}{l}1.11 \\
1.10\end{array}$ & $\begin{array}{l}1.5 \\
1.4\end{array}$ & $\begin{array}{l}1.4 \\
1.0\end{array}$ \\
\hline B2 & $\begin{array}{l}2.0-5.0 \\
5.0-8.0\end{array}$ & $\begin{array}{l}1.07 \\
1.00\end{array}$ & $\begin{array}{l}1.0 \\
0.0\end{array}$ & $\begin{array}{l}1.5 \\
3.4\end{array}$ \\
\hline B3 & $\begin{array}{l}2.0-5.8 \\
5.8-8.0\end{array}$ & $\begin{array}{l}1.12 \\
1.13\end{array}$ & $\begin{array}{l}1.5 \\
1.6\end{array}$ & $\begin{array}{l}0.9 \\
5.5\end{array}$ \\
\hline C & $\begin{array}{l}2.0-3.5 \\
3.5-4.7 \\
4.7-5.7 \\
5.7-6.8 \\
6.8-8.0\end{array}$ & $\begin{array}{l}1.16 \\
1.05 \\
1.09 \\
1.17 \\
1.19\end{array}$ & $\begin{array}{l}1.1 \\
0.4 \\
0.6 \\
1.2 \\
0.6\end{array}$ & $\begin{array}{l}3.7 \\
5.3 \\
9.8 \\
8.8 \\
3.5\end{array}$ \\
\hline
\end{tabular}

age values for each experiment range from onehalf hour to one and one-half hours. This finding was unexpected. Obviously a urea molecule does not require such a long period of time to pass from the glomerulus to the bladder. Furthermore, there is no clear relationship between delay time as calculated and the urine flow. Hence, this derived value does not represent delay due to the time required for passage of fluid from the kidney to the bladder. A systematic analytical error seems unlikely, since similar results were obtained with both $\mathrm{C}^{14}$ and $\mathrm{N}^{15}$, employing different methods for urea determination. Undoubtedly, residual urine in the bladder contributes to the apparent delay in these experiments. But again the absence of a definite relationship between urine flow and apparent delay time indicates that this cannot be the only explanation. A more important factor may be the existence of a pool of urea in the kidney parenchyma with which the excreted urea is in equilibrium. A fall in the specific activity of filtered urea, therefore, would not be reflected in the excreted urea until the specific activity of this pool had reached the same value.

Whatever the explanation, the treatment which follows rests only upon the assumptions: 1) that the specific activity of filtered urea was identical with that of plasma urea; and 2) that the measured discrepancy between plasma and urine specific activity did not change between two and nine hours after injection.

An average value of "delay time" during the first eight hours following injection was calculated for each subject, as shown in Table III.

\section{Calculation of excess tracer excreted during period of equilibrium}

Using the slopes obtained from Figure 1 and the apparent delay times obtained from Table II, the values of the integral,

$$
1-\mathrm{e}^{-(\mathrm{A} / \mathrm{VP})(\mathrm{t}-\mathrm{d})}
$$

can be calculated and plotted against the fraction of the dose excreted, as in Equation 14. The resulting graphs are shown in Figure 2. For each subject a straight line is obtained. The intercepts vary from zero to 20 per cent of the dose. This variation presumably reflects the variable quantities of tracer reaching the kidney during mixing in various experiments. Being

TABLE III

Urea production and metabolism in normal subjects*

\begin{tabular}{|c|c|c|c|c|c|c|c|c|c|c|}
\hline Expt. & Wt. & $\begin{array}{l}\text { Slope } \\
\text { A/VP }\end{array}$ & $\begin{array}{l}\text { Excess } \\
\text { excretion } \\
\mathbf{x} / \mathbf{M}\end{array}$ & $\underset{\mathrm{d}}{\text { Delay }}$ & $\begin{array}{l}\text { Urea } \\
\text { space } \\
\text { V }\end{array}$ & $\begin{array}{l}\text { Pool } \\
\text { VP }\end{array}$ & $\underset{\mathbf{A}}{\text { Production }}$ & $\underset{\mathrm{U}}{\text { Excretion }}$ & $\underset{\mathrm{F}}{\operatorname{Metabolism}}$ & $\underset{\text { F/A }}{\text { Ratio }}$ \\
\hline & $K_{g}$ & $h r .^{-1}$ & $\%$ & $h r$. & $L$ & $G m$ & $\mathrm{Gm} . / \mathrm{hr}$ & Gm./hr. & Gm./hr. & \\
\hline A1 & 74.1 & 0.114 & 13 & 1.0 & 44.9 & 14.5 & 1.64 & 1.29 & 0.37 & 0.20 \\
\hline A2 & 75.5 & 0.105 & 16 & 1.0 & 43.2 & 18.7 & 1.96 & 1.53 & 0.43 & 0.21 \\
\hline B1 & 62.7 & 0.070 & 00 & 1.4 & 38.0 & 13.8 & 0.96 & 0.75 & 0.22 & 0.23 \\
\hline B2 & 59.8 & 0.060 & 05 & 0.5 & 41.8 & 20.0 & 1.19 & 1.04 & 0.15 & 0.13 \\
\hline $\bar{B} 3$ & 60.2 & 0.075 & 04 & 1.6 & 40.2 & 13.0 & 0.98 & 0.62 & 0.36 & 0.36 \\
\hline C & 48.5 & 0.134 & 19 & 0.9 & 27.4 & 12.1 & 1.62 & 1.30 & 0.32 & 0.20 \\
\hline
\end{tabular}

* Subjects $A$ and $B$ received $N^{15}$-urea; Subject $C$ received $C^{14}$-urea. Antibiotic preparation was as follows: A1, $\mathrm{B} 1$ and $\mathrm{C}$, none; A2, succinylsulfathiazole $12 \mathrm{Gm}$. per day for five days followed by chlortetracyline $3 \mathrm{Gm}$. per day for three days; B2, oxytetracycline $2.25 \mathrm{Gm}$. per day for three days; and B3, succinylsulfathiazole $12 \mathrm{Gm}$. per day for six days. 


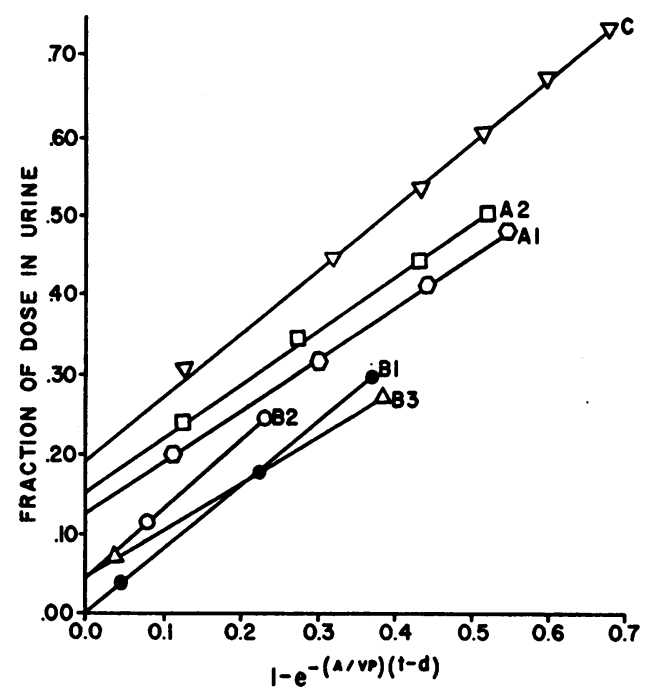

Fig. 2. The Fraction of the Dose of Labeled Urea Recovered in the Urine Plotted Against a Time Integral Which Represents the Fraction Anticipated from the Plasma Disappearance

Subjects $A$ and $B$ received $N^{15}$-urea; Subject $C$ received $\mathrm{C}^{14}$-urea. The intercepts represent the excess excretion of tracer during the period of equilibration.

highly diffusible, labeled urea may, to a large extent, be localized to the systemic organ it reaches on the first circulation, at least for several minutes. If this organ happens to be the kidney, a large fraction will be excreted during the period of equilibration. If it is some other organ, only a small fraction may reach the kidney during this time.

\section{Calculation of volume of distribution, pool size, production rate and the rate of metabolism}

Using the parameters obtained in the previous sections and the equations presented above, one obtains the derived values shown in Table III for the six technically satisfactory experiments, in three subjects, two of whom received $\mathrm{N}^{15}$ - and one $\mathrm{C}^{14}$-urea.

The calculated urea space varies from 56 per cent to 70 per cent of body weight. These values are within the normal range for total body water as a fraction of body weight.

The urea pool of the body varies from 13 to $20 \mathrm{Gm}$. The rate of production varies from 0.96 to $1.96 \mathrm{Gm}$. per hour, and the rate of metabolism from 0.15 to $0.43 \mathrm{Gm}$. per hour. Obviously, all of these values, with the possible exception of urea space, may be expected to vary in a single individual, depending upon protein intake, water turnover and other factors.

The important data in Table III are contained in the last column which shows the ratio of urea metabolized to urea produced. In the control experiments the ratio was $0.20,0.23$ and 0.20 in the three subjects. Following administration of tetracycline derivatives and/or the unabsorbable sulfonamide, succinyl-sulfathiazole, no consistent changes in this ratio were observed in Subjects A or B. This result is compatible with the urea recovery data presented below which indicate that these drugs did not eliminate bacterial ureolysis in the gut. Unfortunately no technically satisfactory experiments of the production rate type were obtained during intestinal bacteriostasis with neomycin.

The data presented in Table III indicate that approximately one-fifth of the urea being synthesized in normal subjects is continually being destroyed. Ninety-five per cent confidence limits for the estimates of production rate in Experiment $\mathrm{C}$, calculated by the method of Halperin and Walser (14) are 1.49 and $1.84 \mathrm{Gm}$. per hour. Since the rate of excretion was $1.30 \mathrm{Gm}$. per hour, the data indicate a significant difference between urea production and excretion, as determined by this statistical test. In the other two control experiments the number of plasma samples obtained was three and four, respectively; consequently application of statistical methods is probably unwarranted.

It may be noted that the calculation of urea space involves the same complications and corrections as the calculation of urea production rate. Therefore, to obtain an accurate estimate of the volume of distribution of urea following a single intravenous injection of tracer, it is necessary to take into consideration both "urinary delay time" and the excess excretion during equilibration. It is possible that these same sources of error might affect the calculation of the volume of distribution of other substances following a single injection. A discussion of this general problem is outside the scope of this work.

\section{The cumulative excretion of labeled urea follow- ing intravenous injection}

In Table IV is presented the total recovery of labeled urea in one experiment with $\mathrm{N}^{15}$ and 14 
TABLE IV

The urinary recovery of labeled urea administered intravenously in normal subjects *

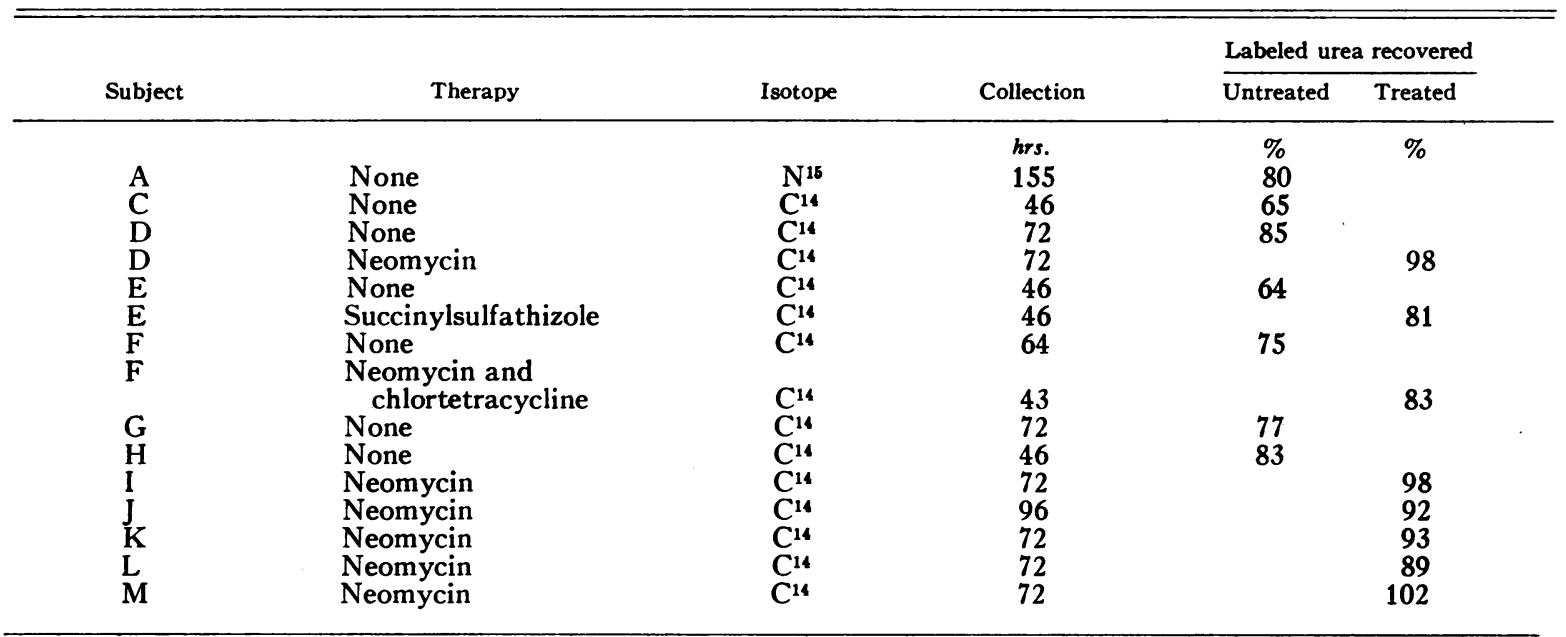

* Neomycin was given $3 \mathrm{Gm}$. per day for two days; succinylsulfathiazole $12 \mathrm{Gm}$. per day for six days; and chlortetracyline $3 \mathrm{Gm}$. per day for three days.

experiments with $\mathrm{C}^{14}$. The period of collection varied from 43 to 155 hours. An approximate estimate of the amount of $\mathrm{N}^{15}$-urea excreted after the first two days may be obtained from examination of Table I. Here 4.1 per cent of the dose was excreted as urea after 32 hours and 2.4 per cent after 56 hours. The results with $\mathrm{C}^{14}$-urea were similar. In Subject G, 7 per cent of the dose was recovered between 45 and 61 hours after injection and 1 per cent between 61 and 77 hours. In Subjects $D$ and I, receiving neomycin, 1 per cent of the dose was recovered between 48 and 72 hours after injection. Presumably, then, the total recovery of labeled urea would have been somewhat greater in those subjects in whom collection was continued for only two days.

Nevertheless the data presented appear to establish : 1) that 15 to 30 per cent of the labeled urea does not appear in the urine in control studies; and 2) that following neomycin therapy, the recovery of labeled urea is significantly increased. Considering only the subjects who received neomycin alone, the mean recovery is 95 per cent.

\section{The presence of reformed $N^{15}$-urea in plasma}

It has been pointed out that reincorporation of labeled carbon or nitrogen atoms into urea is the chief complication of the calculation of production rate. Such reincorporation is itself evi- dence for metabolism, but the methods employed above do not distinguish between labeled urea which was injected as such and labeled urea molecules formed by reincorporation of labeled atoms into newly synthesized urea.

As an incidental finding in this study, it was found that $\mathrm{N}^{15}$-urea molecules injected can be distinguished from urea molecules containing $\mathrm{N}^{15}$ formed anew. The basis of this procedure lies in the existence of three types of urea molecules: those containing two $\mathrm{N}^{14}$ atoms, one $\mathrm{N}^{14}$ and one $\mathrm{N}^{15}$ atom, and two $\mathrm{N}^{15}$ atoms. The statistical distribution of these three types of molecules depends upon simple probability in a random mixture. In normal urea, only a minute fraction of the molecules contains two $\mathrm{N}^{16}$ atoms. In urea containing 60.9 atoms per cent $\mathrm{N}^{15}$, this type of molecule predominates. Therefore, following injection of labeled urea, the proportion of these molecules is higher than would be expected from a random distribution. Newly formed urea containing $\mathrm{N}^{15}$ is composed of all three types in random distribution. Therefore, as the turnover of labeled urea proceeds, the proportions of the three types approach a normal statistical distribution. By reacting urea directly with hypobromite, it is possible to determine the proportion of the three types of molecules present (15).

Urine was collected between three and 12 hours 
after injection of $25 \mathrm{mg}$. of $\mathrm{N}^{15}$-urea in Subject A. Urea was isolated by extraction of the moist residue with hot acetone. A portion of this material was allowed to react directly with hypobromite and another portion was analyzed after Kjeldahl digestion. The ratio of $\mathrm{N}_{2}{ }^{29}$ to $\mathrm{N}_{2}{ }^{28}$ in the two samples was 0.0580 and 0.0305 , respectively. Using these data and the formula for statistical distribution of the three types of molecules, it is possible to calculate the proportion of enrichment due to injected tracer and the proportion due to resynthesized urea (15). This calculation indicates that 15 per cent of the $\mathrm{N}^{15}$ enriched urea was newly formed, the remainder corresponding in statistical distribution to the injected material. The true rate of urea metabolism is therefore greater than indicated by the methods employed above, which fail to distinguish between injected tracer and reformed labeled urea.

\section{DISCUSSION}

These experiments indicate that in man, as in animals, a considerable fraction of synthesized urea is continuously being degraded by intestinal bacteria. Several lines of evidence are presented in support of this conclusion: 1) The estimated rate of urea production exceeded the measured rate of urea excretion by approximately 20 per cent ; 2) the recovery of labeled urea in the urine following intravenous injection was incomplete; 3) 10 per cent of the excess $N^{15}$ appeared in urinary ammonia and nonurea, nonammonia nitrogen following administration of $\mathrm{N}^{15}$-urea in one experiment; 4) a significant fraction of the labeled urea molecules in plasma following $\mathrm{N}^{15}$ urea administration was found to be newly synthesized; and 5) the recovery of labeled urea in the urine became nearly complete following oral administration of neomycin.

These data do not permit a precise estimate of the fraction of synthesized urea which is destroyed. The reappearance of labeled nitrogen or carbon atoms in newly formed urea tends to reduce the apparent rate of urea metabolism. The magnitude of this error is difficult to estimate. In the case of $\mathrm{N}^{15}$, it is clearly considerable. The only evidence for a similar reincorporation of $\mathrm{C}^{14}$ atoms consists of the slow component in the disappearance of $\mathrm{C}^{14}$-labeled urea from the plasma and the urine. The rate of urea production estimated with $\mathrm{C}^{14}$-urea in one subject was similar to that estimated with $\mathrm{N}^{15}$ in the other two. However, one would expect labeled nitrogen precursors to gain access to synthesized urea much more readily than labeled carbon dioxide.

The mathematical procedure employed to calculate production rate tends to minimize the estimated rate, in comparison with other alternative calculations. For example, if the extrapolated plasma specific activity at the time of injection is employed to compute the urea space and urea pool, neglecting the excess tracer excreted during equilibration, higher values for production rate are obtained in five of six experiments. If the "apparent urinary delay time" is overlooked, the calculated production rate is again greater. The average ratio of 0.2 for urea metabolized to urea synthesized in the control studies therefore represents a minimum; the true value of this ratio may be considerably greater.

Since urea recovery following neomycin administration was not quite complete, the possibility remains that a small portion of the observed urea metabolism is due to other metabolic transformations. Kornberg and Davies (5) have demonstrated the absence of urease activity in mammalian tissues other than the gut, and have also calculated that the rate of spontaneous urea hydrolysis is insufficient to account for appreciable breakdown. Other conceivable metabolic pathways for urea include reversal of urea synthesis (1) and transamidation with arginine or creatinine. Creatinine was isolated (16) from the urine obtained between three and 12 hours after injection of $25 \mathrm{mg}$. of $\mathrm{N}^{15}$-urea in a normal subject. The enrichment of creatinine nitrogen was 0.002 atoms per cent excess compared with 0.058 atoms per cent excess in urea excreted during the same interval. Thus, there is no evidence that urea undergoes any metabolic transformations in the body other than hydrolysis within the gut. The small amount of labeled urea not recovered following neomycin may have been excreted in the sweat or in the stool.

It has been established that the removal of ammonia from the blood is defective in the presence of liver disease (17), and that intestinal bacteriostasis diminishes the toxic symptoms of patients with impending hepatic failure (18). It 
is therefore of some interest to calculate the amount of ammonia released into the portal venous blood by urea hydrolysis. The estimated rate of urea breakdown in the three control studies averaged $0.3 \mathrm{Gm}$. per hour or $7.2 \mathrm{Gm}$. per day. This is equivalent in nitrogen content to $11 \mathrm{Gm}$. per day of $\mathrm{NH}_{4} \mathrm{Cl}$. It is possible that the major beneficial effects of neomycin therapy in cirrhotics are attributable to reduction of bacterial urease.

The observations reported are also pertinent to the use of urea as a measure of total body water. The requirements of an ideal substance for measuring total body water include the absence of metabolic breakdown. The assumption that urea is not metabolized underlies the use of large doses of ordinary urea to measure total body water (19). The demonstration of significant breakdown of urea in man appears to invalidate this method but does not necessarily invalidate the use of labeled urea for this purpose. If the extrapolated plasma concentration at time zero is a true measure of the concentration which would have obtained had equilibration been instantaneous, then the derived value for urea space is an accurate one, whether or not metabolic breakdown occurs. The problem is, therefore, that of obtaining a reliable estimate of $M_{o}$, the amount of labeled urea which corresponds to the extrapolated plasma concentration at time zero. As pointed out above, the principle uncertainties are the excess urinary excretion during equilibration and apparent urinary delay. If both of these phenomena are neglected in calculating urea space, that is, if the observations on urine are omitted entirely, the estimated urea space would be zero to 20 per cent greater in the six studies illustrated in Figure 1. These corrections are therefore necessary when the tracer is administered by single intravenous injection. When these corrections are made, the calculated urea space should provide an accurate measure of the true volume of distribution of urea.

It remains to be demonstrated that the concentration of urea in body water is, for practical purposes, uniform. Although there are specialized phases of body fluids with different urea concentration such as the cerebrospinal fluid, the aqueous humor, the renal medulla and the epithelium of the urinary tract, the volume of these phases is too small to introduce significant errors into the estimation of total body water with labeled urea. Of greater importance is the urea concentration in the major portion of cell water. Although reliable measurements are not available, it is generally held that urea is freely diffusible in the water of body cells, with the above exceptions.

It may be concluded, therefore, that labeled urea deserves further trial as a measure of total body water. In subjects in whom the disappearance of labeled material from blood is a simple exponential function, a reliable estimate of urea space may be obtained. The identity of urea space and total body water is likely, but remains to be conclusively demonstrated.

\section{SUMMARY}

Urea labeled with $\mathrm{N}^{15}$ or $\mathrm{C}^{14}$ was injected intravenously into normal subjects and its disappearance from blood and urine was observed. The calculated rate of urea production exceeded the measured rate of urea excretion by 20 per cent. Approximately one-fourth of the labeled urea was not recovered in the urine. The true rate of urea breakdown is probably greater, since evidence was obtained that labeled atoms of $\mathrm{N}^{15}$, and possibly $\mathrm{C}^{14}$, were reincorporated into urea. Following oral neomycin administration, the urinary recovery of $\mathrm{C}^{14}$-labeled urea became nearly complete.

It is concluded that at least one-fourth of synthesized urea is continuously being hydrolyzed by intestinal bacteria in normal subjects.

\section{ACKNOWLEDGMENTS}

We are greatly indebted to Dr. J. A. Sendroy, Jr. for making available the facilities of the Division of Chemistry, Naval Medical Research Institute; to Mr. James George, Dr. W. J. McCarville and Mr. William Comstock for assistance with various phases of this work; and to Dr. Dewitt Stetten, Jr. and Dr. Robert W. Berliner for helpful advice.

\section{REFERENCES}

1. Leifer, E., Roth, L. J., and Hempelmann, L. H. Metabolism of $\mathrm{C}^{14}$-labeled urea. Science 1948, 108, 748 .

2. Dintzis, R. Z., and Hastings, A. B. The effect of antibiotics on urea breakdown in mice. Proc. nat. Acad. Sci. (Wash.) 1953, 39, 571. 
3. Chao, F. C., and Tarver, H. Breakdown of urea in the rat. Proc. Soc. exp. Biol. (N. Y.) 1953, 84, 406.

4. Liu, C. H., Hays, V. W., Svec, H. J., Catron, D. V., Ashton, G. C., and Speer, V. C. The fate of urea in growing pigs. J. Nutr. 1955, 57, 241.

5. Kornberg, H. L., and Davies, R. E. Gastric urease. Physiol. Rev. 1955, 35, 169.

6. Rust, J. H., Visek, W. J., and Roth, L. J. Carbon dioxide fixation and urea synthesis in the rat. J. biol. Chem. 1956, 223, 671.

7. Bloch, K., and Schoenheimer, R. The biological precursors of creatinine. J. biol. Chem. 1941, 138, 167.

8. Van Slyke, D. D., and Cullen, G. E. The determination of urea by the urease method. J. biol. Chem. 1916, 24, 117.

9. Conway, E. J. Micro-Diffusion Analysis and Volumetric Error. London, C. Lockwood, 1947.

10. Berkson, J., Keating, F. R., Jr., Power, M. H., and McConahey, W. M. Determination of the renal clearance of radioiodine. J. appl. Physiol. 1950, 2, 522.

11. Rabinowitz, J. L., Sall, T., Bierly, J. N., Jr., and Oleksyshyn, $\mathrm{O}$. Carbon isotope effects in enzyme systems. I. Biochemical studies with urease. Arch. Biochem. Biophys. 1956, 63, 437.
12. Kornberg, H. L., Davies, R. E., and Wood, D. R. Measurement of total body-water with urea. Nature (Lond.) 1952, 169, 502.

13. San Pietro, A., and Rittenberg, D. A study of the rate of protein synthesis in humans. I. Measurement of the urea pool and urea space. J. biol. Chem. 1953, 201, 445.

14. Halperin, M., and Walser, M. The reliability of estimated rates of production in simple turnover experiments. Arch. Biochem. 1957, 70, 141.

15. Walser, M., George, J., and Bodenlos, L. J. Altered proportions of isotopes of molecular nitrogen as evidence for a monomolecular reaction. J. chem. Phys. 1954, 22, 1146.

16. Bloch, K., and Schoenheimer, R. Studies in protein metabolism. XI. The metabolic relation of creatine and creatinine studied with isotopic nitrogen. J. biol. Chem. 1939, 131, 111.

17. Singh, I. D., Barclay, J. A., and Cooke, W. T. Bloodammonia levels in relation to hepatic coma and the administration of glutamic acid. Lancet 1954, 1, 1004.

18. Falcon, W. W., and Fisher, C. J. Clinical experience with the use of neomycin in hepatic coma. Arch. intern. Med. 1959, 103, 43.

19. Steffensen, K. A. Some determinations of the total body water in man by means of intravenous injections of urea. Acta physiol. scand. 1947, 13, 282. 